\title{
Ahmet Hamdi Tanpınar'ın "Her Şey Yerli Yerinde" Adlı Şiirini Özdeşleyimci Kurama Göre Okuma SENEM GEZEROĞLU*
}

Öz

İnsanın nesneyle kurduğu bağı ve kurulan bu bağ sonucu kişinin o objeyle özdeşleşmesini inceleyen Einfühlung (Özdeşleyim) kuramı, süjenin söz konusu objeye bir duygu hâli yüklemesiyle ilgilenir. Temel ilkeleri Thedore Lipps tarafından oluşturulan Özdeşleyim kuramına göre insanlar birçok nesne, durum, olayla karşı karşıya kalır ve bunlardan etkilenir. Özne, etkileşimde bulunduğu nesneye bir duygu hâli yükler ve nesne de "kendisine bakan"ın duygularıyla anlamlandırılır. Ahmet Hamdi Tanpınar da "Her Şey Yerli Yerinde" adlı şiirinde eşyaya bir duygu hâli yüklemiş ve şiirini "nesne" odaklı söylemler üzerine kurgulamıştır. Eşyaları parnasizimde olduğu gibi mutlak gerçeklik ilkesiyle değil, onlara bir duygu hâli yükleyerek sembolik bir anlatımla kullanan Tanpınar, aynı zamanda eşyalarla şiir öznesi arasında bir özdeşleyim kurarak öznenin duygu durumunu nesne üzerinden anlatmış; nesneyi de anlatının dinamik bir unsuru, odak noktası olarak anlatının merkezine koymuştur.

Anahtar sözcükler: Özdeşleyimci Kuram, "Her Şey Yerli Yerinde”, Ahmet Hamdi Tanpınar, özne, nesne-eşya.

\section{Abstract \\ THE ANALYSIS OF AHMET HAMDİ TANPINAR'S POEM “HER ŞEY YERLİ YERINDE" IN THE CONTEXT OF THE EINFÜLUNG THEORY}

The Einfülung Theory, which examines the correlation between subject and object and the identification of the subject with the object arising from this correlation, focuses on the transfer of a state of feeling by the subject to the object. According to Einfülung theory, whose main principles are created by Thodore Lips, people expose to many objects, cases and events, and are effected by them. Subject loads a state of feeling on the object in which it interacts and object is also sensed by the emotions of the subject who looks to it. Ahmet Hamdi Tanpınar also loads a state of feeling on his poem titled "Her Şey Yerli Yerinde" and fictionalized it through "object" oriented discourses. Tanpınar, who uses the objects with a symbolic expression as in Parnassism by loading a state of feeling on them instead of having an absolute realism principle, explains the subject's emotional state through the object and

\footnotetext{
* Millı̂ Eğitim Bakanlığı, ebced158@hotmail.com
} 
locates object -as a dynamic component of the narrative or a focal point- in the center of narrative by establishing an identification between poem's subject and objects.

Keywords: Einfülung Theory, "Her Şey Yerli Yerinde", Ahmet Hamdi Tanpınar, subject, object.

\section{Gíriş}

- nsanlar gündelik hayatta nesnelerle birtakım ilişkiler kurup bu ilişki sonucunda

$\mathrm{I}$ etkileşim oluştururlar. Kişinin karşılaştığı nesneye yüklediği anlamlar ve nesnenin

kişide uyandırdığı duygular, bu etkileşimin bir parçasıdır. Temelini ise öznenin nesneye bir duygu hâli yüklemesi oluşturur. Esasen güzellik ya da çirkinlik olgusu, nesnede değil ona belli duygularla yaklaşan, kendi bakış açısını yansıtan öznededir. Nesne, kendine bakan öznenin duygularıyla algılanır. Bir metnin kendisi, yazarı ve okuru o bağlamında ise bu süreç, yazarın algıladı̆̆ı nesneye karşı estetik bir haz yaşaması ve bunu eserine yansıtması; okurun ise bu duygu hâlini yeniden yaşamasıyla oluşur. Dolayısıyla okur da nesneye bakarken estetik bir haz duymakta ve bunu sanat eseri aracılığıyla kendi var oluşunda anlamlandırarak özdeşleyim sürecine dâhil olmaktadır. Wilhelm Worringer'in ifadesiyle "Estetik haz, bir objede kendi kendimizden duyduğumuz hazdır" (1985: 30). Nesneye bakan ve onun güzelliğinden hoşlanan suje, aslında kendine ait olan duyguyu objeye yükleyerek suje ve obje arasında bir özdeşim kurar. Thedore Lipps ise özdeşleyimi "kendini kendinden farklı olan yabancı bir objede duymak" (Göknil 1945: 145) olarak tanımlar. Lipps'e göre objede duyulan şey genel olarak yaşamdır. Yani insan, hayatı nasıl yaşıyorsa bir bakıma objeye de öyle bakmaktadır. Özdeşleyim içinde bulunan nesne, öznenin dışındadır. Ancak bu “dışarıda”lık özneden bağımsız değildir. Özne, nesne ile özdeşleyim kurarken aslında kendi niteliklerinden hareket ederek nesneye bakmakta ve sonuçta kendinden haz duymaktadır. İsmail Tunalı bu kavramı şöyle yorumlar:

“Özdeşleyim, günlük yaşamda da sık sık karşılaştığımız, yaşadığımız bir duygu türüdür. İnsan kendini çevreleyen nesnelerle ilgi içindedir. Bu ilgi kimi zaman özel türden bir duygu ilgisi niteliği elde eder. Böylece nesneler ile aramıda duygusallığa dayalı, nesnelerle bir özdeş olma süreci doğar. Bu süreç nesnelerle aramızda bir duygu birliği yaratarak bizim nesnelere duygusallık yüklememizle oluşur. Bunun sonucunda nesneler tıpkı insanlar gibi duygusal bir canlılık kazanır. Söz gelişi, dalgalı bir denize bakıp, 'azgın, coşkun deniz'; yalçın kayalı dağ doruklarına bakıp 'mağrur dağ başları' deriz. Nesnelere yüklemiş olduğumuz bu nitelikler azgınlık, coşkunluk, mağrurluk vb. bütün bunlar bize ait, bizim ruhsal yaşamımıza ait niteliklerdir. Biz bu nitelikleri dağa, denize yükleriz. Biz kendi ruhsal-duygusal yaşamımızla bizim dışımızda bulunan bu nesneler arasında içten bir ilgi kurar, duygularımızda bulduğumuz coşkunluk, mağrurluk gibi nitelikleri 
nesnelere aktarır ve sonra sanki bu nesneler, bu niteliklere sahipmiş gibi, onları bize ait bu nitelikler içinde kavrar ve yaşarız. İşte nesnelerle böyle duygusal bir özdeşlik ilgisi kurmaya özdeşleyim (Einfühlung, Emphaty) olayı denir." (1996:40-41)

Özdeşleyim kuramına göre insan, nesneleri kendi ruh hâline göre niteler. Nesnelere yüklemiş olduğumuz özellikler aslında kendimize ait özelliklerdir. Geçmişe dair yaşantılar, deneyimler ve çă̆rışımlar bütünüdür. Ayrıca kişinin psikolojisi ile de yakından ilgilidir.

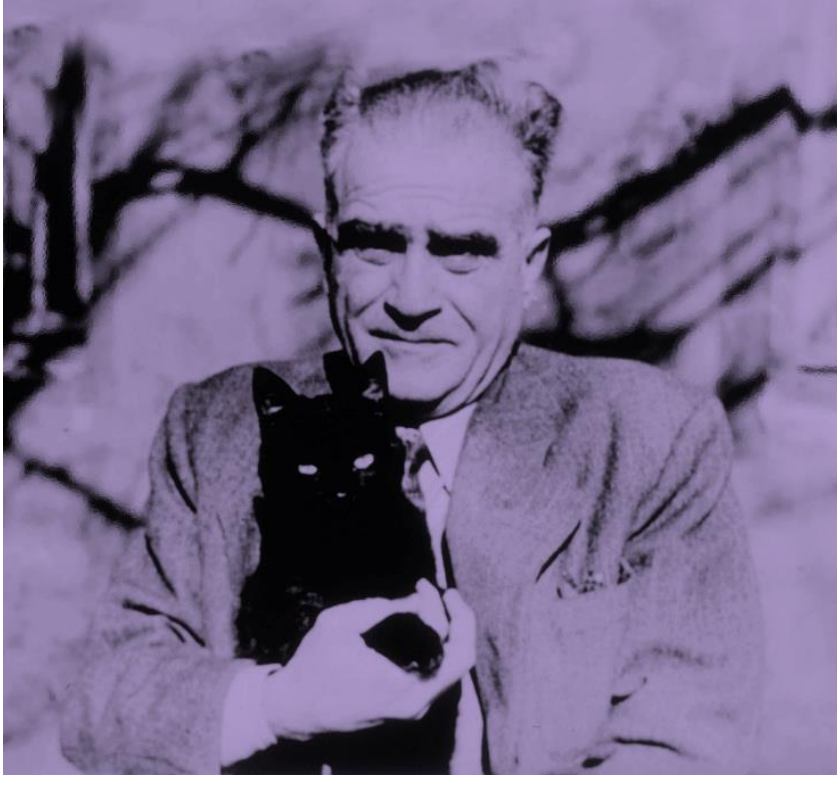
“Örneğin, yıkık bir sütun karşısında duyduğumuz eziklik, sütuna değil, kendimize ait bir duygudur. Ama bu eziklik duygusunu kendimizde değil, o yıkık sütunda yaşarız. Yine ulu bir çınar ağacı karşısında duyduğumuz yücelik duygusu, bize ait bir duygudur, ama bu duyguyu biz kendimizde değil, çınar ağacında yaşarız" (Kolcu 2011: 147).

Görüldüğü gibi, özdeşleyim sürecinde nesnenin özellikleri, kişinin duygu hâlinde önemli bir etken olmuştur. Ancak bunun yanı sıra öznenin psikolojik durumu da özdeşleyimi etkileyen değişkenlerden biridir. İnsanın nesnelerle olan ilişkisini iç dünyasının öncelikleri belirler. Sözgelimi herhangi bir kalem (nesne), kendisine bakan insanların (özne) psikolojik durumlarına göre farklı şekillerde anlamlandırılacaktır. Buna göre öznenin nesneye bakışından hareketle ve Özdeşleyimci kuramın temel ilkeleriyle "Her Şey Yerli Yerinde"yi incelemek ve şiir için yeni bir okuma alanı yaratmak bu çalışmanın esas amacı olacaktır.

\section{ÖZDEŞLEYIM KURAMI BAĞLAMINDA “HER ŞEY YERLİ YERINDD”}

Ahmet Hamdi Tanpınar'ın "Her Şey Yerli Yerinde" adlı eseri, şiir anlatıcısının karşılaştığı nesneye yüklediği anlamlar bakımından önemlidir. Şiirin genelinde "şey"e odaklanan ve eserini bu minvalde oluşturan Tanpınar, eşyalara şiir anlatıcısının duygu hâlini yükleyerek özne-nesne arasında bir iletişim ve daha da ötesinde özdeşleyim kurar:

Her şey yerli yerinde; havuz başında servi

Bir dolap gicirdiyor uzaklarda durmadan,

Eşya aksetmiş gibi tılsımlı bir uykudan.

Sarmaşıklar ve böcek sesleri sarmış evi.

Her şey yerli yerinde; masa, sürahi, bardak,

Serpilen aydınlıkta dalların arasından

Büyülenmiş bir ceylân gibi bakıyor zaman

Sessizlik dökülüyor bir yerde yaprak yaprak. 
Biliyorum gölgede senin uyuduğunu

Bir deniz mağarası kadar kuytu ve serin

Hazların âleminde yumulmuş kirpiklerin

Yüzünde bir tebessüm bu ağır öğle sonu.

Belki rüyalarındır bu tâze açmış güller,

Bu yumuşak aydınlık dalların tepesinde.

Bitmeyen aşk türküsü kumruların sesinde;

Rüyası ömrümüzün çünkü eşyaya siner.

Her şey yerli yerinde bir dolap uzaklarda

Azapta bir ruh gibi gicirdiyor durmadan,

Bir şeyler hatırlıyor belki maceramızdan

Kuru güz yaprakları uçuşuyor rüzgârda. ${ }^{1}$

Ahmet Hamdi Tanpınar'ın sanat anlayışı genel olarak bu kurama yakındır. Çünkü sanatçı, baktığı her şeyde insan ruhunu arar gördüklerini kendi ruh dünyasının pencerelerinden anlatır, ortaya çıkan şeyse sanat eseridir. Tanpınar gerek şiirlerinde gerekse nesirlerinde hayatın dış görüntülerini ve zahir hikâyelerini değil insan ruhunun ve yaşamın sırlarını arar. Kendisi de bir denemesinde şöyle der: “Hakiki şiirin, asıl sanat eserinin kendi varlığından başka hedefi yoktur. Kendisinde başlar, kendisinde biter. Bütün asaleti de buradan gelir. Ondan beklenilecek yegâne şey, bizde bediî alâka dediğimiz ve hayatımızın maddî taraflarıyla, gündelik endişeleriyle münasebettar olmayan saf bir alâka uyandırmasıdır." Görüldüğü gibi sanatçı, kendisi dışındaki herhangi bir şeye bakarken yine kendisinden hareket ederek kendisiyle alâkalı bir şey arar. İnsan, bir öznedir ve bir obje olan eşyaya baktığı zaman onu yine kendi dünyasından yorumlar. Dolayısıyla ortaya çıkan sanat eseri kendinden bağımsız değildir, eşya kendisine bakana göre şekillenmektedir.

Ahmet Hamdi Tanpınar'ın "Her Şey Yerli Yerinde" adlı bu şiirinde eşyaya dair bir vurgu yapılmaktadır. "Eşya aksetmiş gibi tılsımlı bir uykudan" ya da "Rüyası ömrümüzün çünkü eşyaya siner" gibi söylemler, şiir anlatıcısının eşyaya özel anlamlar yüklediğine işarettir. Şiirde başlık olarak kullanılan ve yer yer tekrarlanarak önemine vurgu yapılan "her şey yerli yerinde" söylemi, eşyanın statik oluşunun bir ifadesidir. "şey", Türk Dil Kurumu'nun Güncel Türkçe Sözlük'ünde "1. isim Madde, eşya, söz, olay, iş, durum vb. nin yerine kullanılan, belirsiz anlamda bir söz, 2. Nesne, madde" olarak geçmektedir. Şiirin

\footnotetext{
${ }^{1}$ Ahmet Hamdi Tanpınar, Bütün Şiirleri, s. 40
} 
manzaradan hareketle zamanın yaz, mekânın ise tenha bir ev olduğunu söylemek mümkündür. Zaman ve mekân durmuş, eşya ise "tılsımlı bir uyku"dan aksetmiştir. Zamanın yutan boşluğundan ve mekânın hapseden sınırlarından kaçarak âdeta hayatta kalmak, daha uzun yaşamak ister. Bu bir anlamda zamana ve mekâna sıkışan insanın huzur arayışıdır. Şiir anlatıcısı da, "Sessizlik dökülüyor yaprak yaprak" diyerek sessizliğin içindeki sesi dinler ve dinleyişte ruhunu nesneye yansıtarak eşyalarla etkileşim sürecine girer. Özne, sujeye kendinden bir değer yükleyerek ve sujeyi o şekliyle anlamlandırarak bir bakıma huzurunu eşyalarda arar. Öyle ki, devam eden misralarda bir huzur manzarası çizilmektedir:

Biliyorum gölgede senin uyuduğunu

Bir deniz mağarası kadar kuytu ve serin

Hazların âleminde yumulmuş kirpiklerin

Yüzünde bir tebessüm, bu ağır öğle sonu

Anlatıcının hitap ettiği sen öznesi, psikanalitik açıdan da anne karnına benzeyen deniz mağarası kadar kuytu ve serin bir yerde, id'in gerçeklerine uygun olarak haz almaktadır. Çiçekler, dallar ve kumrularla birlikte çizilen manzara ile ömür bir rüyaya benzetilmekte, insan algısının bir parçası olan bu rüyalar ise ancak eşyada iz bırakabilmektedir. Dolayısıyla insanı huzursuzluğa sokan her türlü şeyden uzaklaşmak ve bir rüya miktarınca huzura yaklaşmak eşyaların aracılığıyla olmaktadır. "Rüyası ömrümüzün çünkü eşyaya siner" dizesi, bu açıdan şiirin bel kemiğini oluşturur.

Kişinin eşyayla kurduğu bağ sonucunda o eşyayla özdeşleşmesi, özne ve nesne arasında bir iletişimin de başlangıcı olur. Bu iletişim sürecinde suje, farkında olarak ya da olmayarak objeyi kişileştirme yoluna gider. Gören ve görülen arasında yaşanan bu iletişim ve özdeşleyim sonucuda, görenin yani öznenin, görülene yani nesneye yüklediği değerle birlikte, eşya insansı özellikler kazanır. Çünkü özne, nesne ile bir bütün olma, kendi özdeşini karşı tarafta görme ve yaşatma eğilimindedir. John Berger, Görme Biçimleri adlı kitabında görme ve görülmeye dair şunları söyler:

“Bir şeyi gördükten hemen sonra, aynı zamanda kendimizin görülebileceğini de fark ederiz. Karşımızdakinin gözleri bizimkilerle birleşerek görünenler dünyasının bir parçası olduğumuza bütünüyle inandırır bizi. Karşıdaki tepeyi gördüğümüzü kabul edersek o tepeden görüldüğümüzü de kabul etmemiz gerekir." (2013: 9)

Şiirde de "Serpilen aydınlıkta dalların arasından/ Büyülenmiş bir ceylan gibi bakıyor zaman" ifadesinde kendini belli eden ve şiirin başından beri süregelen zamanın ve mekânın nesneleşmesi olayı, özdeşleyim kavramıyla açıklanabilir. Kişi, eşyalar aracılığıyla zamana ve mekâna da kendi duygu hâlini yükleyerek onları da özdeşleyim sürecine dâhil etmiş olur. "Her şey yerli yerinde; masa, sürahi, bardak" diyen şiir anlatıcısının durağan nesneler 
seçmesi ve ardından "donmuş zaman"1 büyülenmiş bir ceylanla ifade etmesi, bunun yanı sıra sessiz mekânları tasvir etmesi ruhtaki dinginlik arayışının eşyaya yansımış hâlidir. Bu hâl de özdeşleyim sürecinin bir parçasıdır. Çünkü, "Düşündüklerimiz ya da inandıklarımız nesneleri görüşümüzü etkiler" (Berger 2013: 8). Şiirde seçilen eşyalar kadar, onları kullanış ve ifade ediş biçimi de önem arz eder. Şiir anlatıcısının yani öznenin, objeye yüklediği değer ve anlamın yanı sıra, seçilen nesnenin hangi kategoride ele aldığı da önemlidir. Aslı Uçar, “Teselliyi Eşyada Aramak: Türkçe Romanda Nesneler" adlı çalışmasında nesne-karakter, karakter-nesne, nesnemsi, metonimik nesne ve metaforik nesne olmak üzere nesnenin anlatıya yansıyan durumunu ve insan-nesne ilişkisini beşe ayırır. Eşyanın kişileştirilmesine nesne-karakter adı verilirken insanın şeyleşmesi ya da nesneleşmesi karakter-nesne olarak anlandırılır. Karakterleri bir araya getiren ve bu yönüyle toplumsal bir rol oynayan nesneler ise nesnemsi kategorisinde incelenir. Nesneler arasinda ya da nesne/kavram/kişi arasında olumsal ya da çağrışımsal ilişki kurma biçimi "metonimik nesne" olarak adlandırılırken, benzetilen ile benzeyenin somut bir nesne olduğu durumlar "metaforik nesne" kavramiyla ifade edilir (2012: 45-60). "Her Şey Yerli Yerinde"nin genelinde anlatıcının kullandığı obje türü nesne-karakter veya metaforik nesnedir. Şiirin son bölümüde kullanılan dolap, hem bir "ruh"a benzetilerek metaforlaştırılmış ve "metaforik nesne" özelliği kazanmış hem de acı çekme özelliğiyle kişileştirilerek bu yönüyle de "nesnekarakter" özelliği üstlenmiştir:

Her şey yerli yerinde; bir dolap uzaklarda

Azapta bir ruh gibi gicırdiyor durmadan.

Zamanın ve mekânın durduğu bir sakinlikte her şey yerli yerindeyken, eşyalar bile sessizliğe bürünmüşken "azapta bir ruh gibi” gıcırdayan dolap, bir başka özdeşleyimin nesnesidir. Özdeşleyimci kuramda üzerinde durulması gereken konulardan biri de süjenin psikolojik durumudur. Ali İhsan Kolcu, “Özdeşleyim her şeyden önce psikolojik bir olaydır. İnsanın nesnelerle ilişkisini iç dünyasındaki öncelikler ve estetize olmuş durumlar belirler" (2011: 148) der. Aynı dolap yani aynı nesne, bir başka özne için belki de çok farklı anlamları çağrıştırırken bu şiirde, şiir anlatıcısı için "acı çeken bir ruh" konumundadır. Bu da tecrübenin (öğrenilmişlik) ve çağrışımın yanı sıra, süjenin psikolojik durumuyla yakından ilgilidir. Dolayısıyla öznedeki bu psikolojik değişim, nesneyle kurulan ruhsal ve duygusal ilişkinin de ifade biçimini belirler. Şiirin devamından da anlaşılacağı üzere dolabın acı çekerek gıcırdamasına (inleyen insan) sebep, bir bakıma rüzgârdır. Rüzgâr ise kuru 
yaprakları, yani hatıraları ortaya çıkaran, kimi zaman savuran zaman imgelemi ile kullanılmıştır. Ancak bu kısımda özdeşleyim açısından üzerinde durulacak esas nokta, kendi ruhunu gicırdayan, inleyen bir dolaba benzeten şiir öznesidir. Öznenin karakteri, bilgi ve deneyimi, psikolojik durumu vb. nitelikler, eşyaya bakışını ve onu algılayışını etkiler. Kendi başına nötr olan eşya, kendisini algılayanın dünyasına göre anlam kazandığı için özdeşleyimde esas unsurun "nesne" değil "özne" yani "eşya" değil "insan" olduğunu söylemek mümkündür.

\section{SONUÇ}

Özdeşleyim kuramından hareketle yeniden okunan "Her Şey Yerli Yerinde"de, eşyaların gelişigüzel ya da sadece "mutlak gerçeklik" ilkesiyle kullanılmadığı, anlatıcının nesneye belli anlamlar yüklediği görülmüştür. Şiirde kullanılan eşyalar, "kurmaca nesneler" olarak ele alınmış ve anlatım açısından gereksiz görülmeyip şiirin kurgusu, konusu ya da mesajı için belli bir işlevle oluşturulmuştur. Bu işlevden hareketle Özdeşleyim kuramında yer alan nesnelerin rolleri ve öznelerin halleri, özne-nesne arasındaki ilişki gibi kavramlar üzerinde durulmuştur. Sonuç olarak anlatıcının eşyaları ifade ederken gelişigüzel bir yol takip etmediği, kimi zaman özneyi ve öznenin psikolojik durumunu nesne üzerinden anlattığı, nesneyi de eşya betimlemesinden ziyade anlatının dinamik bir parçası ya da odak noktası olarak ele aldığı görülmüştür.

\section{KAYNAKÇA}

Ayvazoğlu, Beşir (2002). Aşk Estetiğ i. İstanbul: Ötüken Yayınları.

Berger, John (2013). Görme Biçimleri. İstanbul: Metis Yayıncılık.

Göknil, Nazan (1945). “Estetik Haz, Psikolojik ve Fenomenolojik Estetik Hakkında Bir Araştırma". Felsefe Arkivi. Sayı 1. İstanbul: İstanbul Üniversitesi Yayınları.

Hitchcock, Louise (2013). Kuramlar ve Kuramcılar. İstanbul: İletişim Yayınları.

Kolcu, Ali İhsan (2011). “Einfühlung Kuramı". Edebiyat Kuramları. Erzurum: Salkımsöğüt Yayınevi.

Tanpınar, Ahmet Hamdi (2009). Bütün Şiirleri. 9. Baskı. İstanbul: Dergâh Yayınları.

Tunalı, İsmail (1996). Estetik. İstanbul: Remzi Kitabevi.

Uçar, Aslı (2012). Teselliyi Eşyada Aramak: Türkçe Romanda Nesneler. Doktora Tezi. Ankara: Bilkent Üniversitesi.

Worringer, Wilhelm (1985). Soyutlama ve Özdeşleyim. Çev: İsmail Tunalı. İstanbul: Remzi Kitabevi. 